\title{
La vacunación antigripal en el personal de salud es efectiva y disminuiría la transmisión a los pacientes de alto riesgo
}

\author{
Effectiveness of Influenza Vaccine in Health Care Professionals. A Randomized Trial.
} Wilde J , Mc Millan J , Serwint J. JAMA 1999; 281 : 908-913

\begin{abstract}
Objetivo
Determinar la efectividad de la vacuna antigripal trivalente en disminuir la infección por influenza, la enfermedad y los días de ausentismo laboral en profesionales de la salud jóvenes y sanos.
\end{abstract}

\section{Diseño}

Estudio randomizado, prospectivo, doble ciego, controlado, con seguimiento por tres años consecutivos (1992-1995).

\section{Lugar}

Dos hospitales escuela de Baltimore, EE.UU.

\section{Participantes}

Se incluyeron 264 profesionales del medio hospitalario menores de 50 años y sin problemas médicos crónicos: 49 participaron por dos períodos invernales, 24 participaron en tres períodos y 191 por un solo período (361 observaciones totales). La edad promedio fue de 28,4 años; $75 \%$ eran médicos residentes y $57 \%$ eran mujeres.

\section{Intervención}

Se aleatorizó a los participantes para recibir la vacuna antigripal o control (vacuna antineumocóccica, antimeningocóccica o placebo). Se tomaron muestras de sangre en el momento de la vacunación, al mes (para determinar la respuesta serológica a la vacuna), y al final de la estación viral (para identificar a los sujetos infectados por los virus de Influenza tipo A o B). La detección de anticuerpos se realizó por inhibición de hemaglutinación, utilizando los antígenos apropiados para Influenza A y B acorde a los estudios epidemiológicos correspondientes a cada período invernal.

Se realizó una vigilancia de enfermedad durante el período de epidemia a través de entrevistas telefónicas semanales.

El período epidémico fue determinado a través de un monitoreo activo virológico intrahospitalario y por datos epidemiológicos obtenidos de fuentes locales, estatales y nacionales.

\section{Medición de resultados principales}

El resultado principal fue la infección por Influenza definida serológi- camente por un incremento de cuatro veces en el título de anticuerpos entre el período post-inmunización y post-epidemia. Los resultados secundarios incluyeron: $\geq 2$ días de enfermedad respiratoria, (dos o más de los siguientes síntomas: rinorrea, tos u odinofagia), días de enfermedad respiratoria febril (reporte de fiebre, con o sin documentación con termómetro) y días de ausentismo laboral.

\section{Resultados principales}

Se realizó la vigilancia serológica en 359 personas de las 361que participaron en los tres períodos invernales ( $99,4 \%$ de seguimiento), y la pesquisa de enfermedad de 4746 personas / semana ( $100 \%$ de seguimiento). Veinticuatro $(13,4 \%)$ de los 179 participantes del grupo control y tres $(1,7 \%)$ de los 180 vacunados tuvieron evidencia serológica de infección por Influenza tipos A y B durante el período de estudio. La efectividad de la vacuna contra la infección serológicamente definida fue del $88 \%$ para Influenza A ( IC95\% 47-97\%, $p=0,001$ ), y del $89 \%$ para Influenza B ( IC95\% 14-9,9\%, $p=0,03$ ). No hubo diferencias significativas en cuanto a personas que reportaran días de enfermedad respiratoria febril (vacunados: $28,7 \%$ vs. $40,6 \%$ en el grupo control $[\mathrm{p}=0,57])$; tampoco fueron diferentes los días de ausentismo $(9.9 \%$ grupo vacunado vs $21,1 \%$ en el grupo control ( $p=0,41)$.

\begin{tabular}{|c|c|c|c|c|}
\hline & \multicolumn{2}{|c|}{ Influenza A (H3N2), No (\%) } & \multicolumn{2}{|c|}{ Influenza B, No (\%) } \\
\hline Año de estudio & Vacuna Antigripal & I Control & Vacuna Antig & ripal Control \\
\hline $1992-1993$ & $2 / 52(3.9)$ & $10 / 50(20)$ & $0 / 52(0)$ & $4 / 50(8)$ \\
\hline 1993- 1994 & $0 / 51(0)$ & $4 / 52(7.1)$ & $0 / 51(0)$ & $0 / 52(0)$ \\
\hline 1994- 1995 & $0 / 77(0)$ & $2 / 77(2.5)$ & $1 / 77(1.3)$ & $5 / 77(6.5)$ \\
\hline $\begin{array}{l}\text { Total } 1992 \\
-1995\end{array}$ & $2 / 180(1.1)$ & $16 / 179(8.9)$ & $1 / 180(0.6)$ & $9 / 179(5.0)$ \\
\hline
\end{tabular}

Infección por Gripe durante epidemias anuales 1992- 1995

\section{Conclusiones}

La vacuna antiinfluenza es efectiva en prevenir la infección por Influenza A y B en profesionales de la salud. Este estudio no logró demostrar diferencias en el ausentismo ni en episodios de enfermedad repiratoria.

Fuente de financiamiento: Instituto Nacional de Salud-Centro Nacional de Investigación Clínica universitario, John Hopkins - Laboratorios Connaught.

\section{COMENTARIO}

En el presente estudio, y consistentemente con otros, la vacuna antigripal es efectiva en la prevención de la infección a virus Influenza A y B en el personal de salud. Las tasas de efectividad (88\%) y de infección en no vacunados $(14 \%)$, son similares a las de estudios previos ${ }^{1}$. No obstante, sería necesario considerar que la serología no detectaría entre un 20-30\% (tasa de falsos negativos) de las infecciones probadas por cultivo. A diferencia de otros trabajos ${ }^{2-3}$, el presente estudio no encontró una disminución estadísticamente significativa ni en la tasa de ausentismo laboral ni en la incidencia de enfermedad respiratoria post-vacunación. Esto se puede deber a una falta de poder ${ }^{\star}$ del presente estudio para detectar estas diferencias, que pueden ser clínicamente significativas. En el estudio de Nichol y col,2-3 los resultados obtenidos son similares en cuanto a eficacia protectora pero la vacunación disminuye el ausentismo laboral y la enfermedad respiratoria. La causa de esta discrepancia, posiblemente tenga un origen multifactorial (la falta de poder ya mencionada, la diferente motivación del personal testeado, distintas exigencias laborales, etc.). Esto justificaría estudios ulteriores que la evalúen. Coincidentemente con trabajos previos, la conversión serológica post-vacunación de

\section{Referencias}

1. Simon, H. Inmunization. Primary Care Medicine. Goroll. 3œEdition. 1995: 20-28

2. K. Nichol, A. Lind, K. Margolis. The Efectiveness of Vaccination against Influenza in Working Adults. New England Journal of Medicine, 0ctober $5,1995$. No $14 ; 333: 890-893$.

3. K. Nichol, K. Margolis, A. Lind. Side effects associated with Influenza vaccination in Healthy Working Adults. Arch. Intern. Med 1996; 156:1546-1550

4. Gentile, A.Consenso de vacunas. .Propuesta para la incorporación de nuevas vacunas al calendario Nacional. 1998.

novo fue mayor que la de los vacunados por segundo año consecutivo (65\% y $30 \%$ respectivamente), sin diferencias en cuanto a la protección y al porcentaje de infección viral entre ambos grupos. Por otro lado, cabe destacar que, si bien la estimación de la tasa de transmisión intranosocomial a pacientes de alto riesgo no era uno de los objetivos de este trabajo, representa uno de los factores que avalarían esta conducta en los profesionales de salud, y podría representar un indicador indirecto de efectividad al interrumpir la cadena epidemiológica. Lamentablemente este estudio se basa en estimaciones previas, pero no muestra de modo objetivo ningún resultado en relación a esto. En conclusión la vacunación antigripal anual en el personal de la salud previene eficazmente la infección viral y debería incorporarse como práctica de rutina; podría disminuir la transmisión a los pacientes de alto riesgo, aunque serian necesarios más estudios que avalen este último punto.

*Ver Glosario

Dra. Gabriela Fabbro

Clínica Médica. Hospital Italiano de Buenos Aires.

Dra. Amalia Scharfner

Sistemas de Protección Médica 